\author{
Jurnal E-Bis (Ekonomi-Bisnis) \\ Vol.5 No.2 (2021) pp. $439-448$ \\ https://jurnal.politeknik-kebumen.ac.id/index.php/E-Bis \\ p-ISSN : 2580-2062 e-ISSN : 2622-3368
}

\title{
Pengaruh Bauran Promosi Terhadap Keputusan Pelanggan Menggunakan Jasa PT. Pos Indonesia (Persero) Cabang Soreang
}

\author{
Hana Aulia Soleha ${ }^{*}$, Prihartono Aksan Halim² \\ ${ }^{12}$ Manajemen Bisnis, Politeknik Piksi Ganesha, Indonesia
}

*Email : hasoleha@piksi.ac.id

Doi : https://doi.org/10.37339/e-bis.v5i2.683

Diterbitkan oleh Politeknik Dharma Patria Kebumen

Info Artikel

Diterima :

2021-08-31

Diperbaiki :

2021-10-01

Disetujui :

2021-10-02

\begin{abstract}
ABSTRAK
Tujuan penelitian ini untuk mengetahui seberapa besar pengaruh dari Bauran Promosi terdiri dari variabel, advertising $(X 1)$, personal selling $(X 2)$, public relations (X3), sales promotion(X4), direct marketing $(X 5)$ terhadap variabel Keputusan Pelanggan. Metode Pengambilan data penelitian dengan menggunakan accidental sampling sebanyak 55 responden. Hasil penelitian disimpulkan bahwa secara simultan variabel advertising, personal selling, public relations, sales promotion, directs marketing berpengaruh signifikan terhadap variabel keputusan pelanggan. Secara parsial variabel personal selling (X2) dan sales promotion $(X 4)$ berpengaruh positif dan signifikan dengan thitung 2.033 dan $2.741>\mathrm{t}$ tabel 2,00958, kemudian variabel advertising $(X 1)$ dan direct marketing (X5) berpengaruh positif dan tidak signifikan dengan thitung 1,538 dan $1.813<\mathrm{t}$ tabel 2,00958, serta pada variabel public relations(X5) berpengaruh negatif dan tidak signifikan dengan thitung $-1.212<\mathrm{t}$ tabel 2,00958 terhadap variabel keputusan pelanggan.
\end{abstract}

Kata Kunci: Bauran promosi, keputusan pelanggan

ABSTRACT

The purpose of this study is to determine how much influence the Promotional Mix which consists of variables, advertising (X1), personal selling (X2), public relations (X3), sales promotion (X4), direct marketing (X5) on the Customer Decision variable.. The results of the study concluded that simultaneously advertising, personal selling, public relations, sales promotion, marketing directs variables had a significant effect on customer decision variables. Partially, personal selling (X2) and sales promotion (X4) variables have a positive and significant effect with tcount 2.033 and $2.741>t$ table 2.00958, then advertising (X1) and direct marketing (X5) variables have a positive and insignificant effect with tcount 1.538 and $1.813<$ t table 2.00958 , and the public relations variable (X5) has a negative and no significant effect with tcount $1.212<t$ table 2.00958 on the customer decision variable.

Keywords: customer decision, promotion mix

\section{PENDAHULUAN}

Jl. Letnan Jenderal Suprapto No.73 Kebumen, Jawa Tengah, Indonesia 55431 
Perusahaan jasa ekspedisi atau layanan pengiriman mempunyai peranan penting untuk meningkatkan perekonomian di Indonesia. Menurut (Kementerian Komunikasi Dan Informatika, n.d.) pada tahun 2019 Negara Indonesia merupakan negara dengan pertumbuhan peminat e-commerce paling tinggi di dunia yakni sebesar $78 \%$, sedangkan Negara Meksiko yang berada di urutan kedua dengan nilai pertumbuhan sebesar 59\%. Tentu peluang pasar tersebut saat ini sudah banyak digunakan oleh beberapa perusahan jasa di Indonesia seperti JNE, Ninja Express, JNT, TIKI hingga Pos Indonesia. Tetapi pangsa pasar di Indonesia saat ini sudah banyak dikuasai oleh perusahaan milik swasta yang telah menyediakan pelayanan yang beragam untuk memberikan kepuasan bagi para pelanggannya melalui biaya pengiriman yang terjangkau, pengiriman cepat, dan memberikan jaminan barang sampai ketangan penerima dengan baik. Hal tersebut tentu mereka lakukan untuk menguasai pangsa pasar yang ada. Sesuai dengan peneliti sebelumnya (Wantu, 2014) mengemukakan bahwa salah satu faktor yang menentukan daya saing memenangkan persaingan tersebut adalah kepuasan dari para pelanggan, karena jika pelanggan merasa tidak puas mereka bisa saja lebih memilih pelayanan jasa pesaing dan kondisi tersebut tentu tidak menguntungkan bagi perusahaan sebab mengakibatkan kerugian dan dapat terjadi penurunan laba bagi perusahaan.

Pos Indonesia merupakan perusahaan pemerintah dibidang jasa pengiriman, pengadaan dan transaksi keuangan. Dalam pelayanan jasa pengiriman Pos Indonesia diharuskan untuk selalu menjaga keutamaan pelayanan pengiriman melalui ketepatan jangka waktu, perluasan jangkauan, serta jaminan layanan antar yang akan mempengaruhi keputusan pelanggan untuk menentukan keputusan memilih jasa pengiriman yang dipilihnya. Hal yang harus dilakukan oleh Pos Indonesia dalam menjaga keutamaan pelayanannya yakni dengan menerapkan bauran promosi yang berkaitan dengan pemasaran dan sesuai dengan tujuan perusahaan.

Tujuan utama kegiatan promosi adalah untuk membujuk, menginformasikan dan memengaruhi calon pelanggan kepada produk yang akan ditawarkan (Tjiptono, 2015). Kegiatan promosi dan komunikasi ini penting bagi perusahaan, karena dengan adanya kegiatan ini para pelanggan dapat mengetahui dan menentukan keputusannya untuk memilih jasa PT. Pos Indonesia (Persero) Cabang Soreang. Berdasarkan permasalahan diatas maka akan dilakukan penelitian yang berjudul Pengaruh Bauran Promosi terhadap Keputusan pelanggan Dengan variabel independent (X) yakni, advertising (X1), personal selling(X2), public relations (X3), sales promotion(X4), direct marketing (X5) serta variabel dependent (Y) yakni keputusan pelanggan. Dengan objek penelitian adalah Pelanggan pengguna layanan jasa Pos Indonesia Cabang Soreang.

\section{KAJIAN PUSTAKA}

\subsection{Bauran Promosi}

Bauran promosi merupakan komponen yang termasuk kedalam bauran pemasaran dan penting dilakukan para pelaku usaha untuk memasarkan produknya dari barang maupun jasa. (Kotler dan Amstrong, 2012), Bauran Promosi yaitu kombinasi alat promosi dipakai suatu perusahaan dalam menginformasikan nilai kepada pembeli serta meningkatkan komunikasi kepada pelanggan. (Kotler dan Amstrong, 2012), menjelaskan promotion mix mempunyai 5 (lima) alat promosi sebagai berikut: 1) Advertising (Periklanan), adalah segala bermacam 
penyajian yang tidak dilakukan oleh orang dalam bentuk promosi ide, jasa, atau barang sponsor yang ditunjuk. 2) Sales Promotion (Promosi Penjualan) adalah beragam penawaran bertujuan menarik konsumen agar membeli jasa maupun produk. 3) Personal Selling (Penjualan Personal), adalah hubungan langsung pada calon pelanggan melalui menjawab pertanyaan, melakukan persentasi, dan memperoleh pesanan. 4) Direct marketing (Pemasaran Langsung), adalah penggunaan media teknologi salah satunya seperti telepon, untuk dapat berkomunikasi secara langsung atau memperoleh tanggapan dengan calon konsumen. 5) Public Relations (Hubungan Masyarakat), adalah seluruh rencana yang disusun dalam mempromosikan setiap produknya, serta menjaga nama baik perusahaan.

\subsection{Keputusan Pelanggan}

Menurut (Tjiptono, 2014), Keputusan pembelian yaitu mekanisme pelanggan mengenali kebutuhannya, memilih informasi produk atau merek produk tertentu. (Kotler dan Amstrong, 2012) pelanggan akan melalui lima tahapan proses dari keputusan pembelian yakni : a) mengenali keinginan, tahapan pertama dimana pelanggan mengenali kebutuhan atau keinginannya. b) memilih informasi, konsumen yang timbul minatnya dan terdorong untuk mencari informasi banyak lagi. c) alternative evaluasi, untuk mengevaluasi alternative merek dalam suatu pilihan sekelompok. d) keputusan membeli, pelanggan memberi keputusan untuk membeli produk yang sesuai keinginannya. serta e) tingkah laku sesudah membeli, pelanggan akan mengalami tingkat kepuasan serta ketidakpuasannya terhadap produk yang sudah dibelinya.

\section{METODE}

Metode penelitian menggunakan metode kuantitatif serta pendekatan deskriptif. (Martono, 2010) menjelaskan penelitian kuantitatif yaitu melakukan penelitian dan mengambil data-data berbentuk angka. Menurut (Sugiyono, 2018) Metode Penelitian deskriptif yaitu melakukan penelitian untuk melihat nilai variabel yang mandiri, dalam satu variabel ataupun lebih (independen). Pengumpulan data primer melalui penyebaran kuesioner, observasi serta wawancara..

\subsection{Populasi dan sampel}

Populasi objek penelitian adalah para konsumen pengguna layanan jasa PT. Pos Indonesia yang berjumlah 55 responden dengan teknik pengumpulan sampel dengan accidental sampling. Pengambilan data dilakukan menyebarkan kuesioner kepada pelanggan PT. Pos Indonesia (Persero) Soreang.

\subsection{Teknik analisis Data}

Teknik analisis data yang digunakan dengan uji asumsi klasik, uji signifikan, analisis regresi linier Berganda dan koefisien determinasi. Pada penelitian ini yang merupakan variabel independent yakni bauran promosi terdiri variabel advertising, personal selling, public relations, sales promotion, direct marketing dan variabel dependent adalah keputusan pelanggan 


\section{HASIL DAN PEMBAHASAN}

Menurut hasil observasi, karakteristik dari pelanggan sebagian besar berjenis kelamin perempuan sebesar $51 \%$. Kemudian berdasarkan karakteristik usia menunjukan, bahwa responden sebagian besar berumur sebanyak 18-25 tahun. Berdasarkan Pada kategori pekerjaan menunjukan bahwa mahasiswa/pelajar paling unggul sebesar 31\%, Buruh 25\%, pengusaha $21 \%$, PNS 9\% dan lainnya sebesar 14\%. (Khusna \& Oktafani, 2017)

\subsection{Uji Asumsi Klasik}

\section{a. Uji normalitas}

Tabel 1. Hasil analisis normalitas

One-Sample Kolmogorov-Smirnov Test

\begin{tabular}{lcc}
\hline & & \\
& & Unstandardized Residual \\
$\mathrm{N}$ & Mean & 55 \\
Normal Parameters ${ }^{\mathrm{a}, \mathrm{b}}$ & Std. Deviation & .0000000 \\
& Absolute & 3.57308480 \\
Most Extreme Differences & Positive & .077 \\
& Negative & .055 \\
Test Statistic & & -.077 \\
Asymp. Sig. (2-tailed) & & .077 \\
\hline
\end{tabular}

Berdasarkan hasil output, diketahui nilai dari signifikansi 0,200 lebih tinggi terhadap nilai alpha yakni $(0,05)$. Dengan demikian diketahui nilai residual berkontribusi normal.

\section{b. Uji Multikolinearitas}

Tabel 2. Hasil multikolinearitas

\begin{tabular}{lll} 
& \multicolumn{2}{l}{ Collinearity Statistics } \\
Variabel & Tolerance & VIF \\
\cline { 2 - 3 } Periklanan & .522 & 1.914 \\
Penjualan Pribadi & .420 & 2.378 \\
Hubungan Masyarakat & .549 & 1.821 \\
Promosi Penjualan & .659 & 1.518 \\
Pemasaran Langsung & .492 & 2.033 \\
\hline
\end{tabular}

Menurut tabel 2 didapat bahwa semua nilai VIF kurang dari 10\% sehingga gejala multikolinearitas tidak ada.

c. Uji Heteroskedasitas 


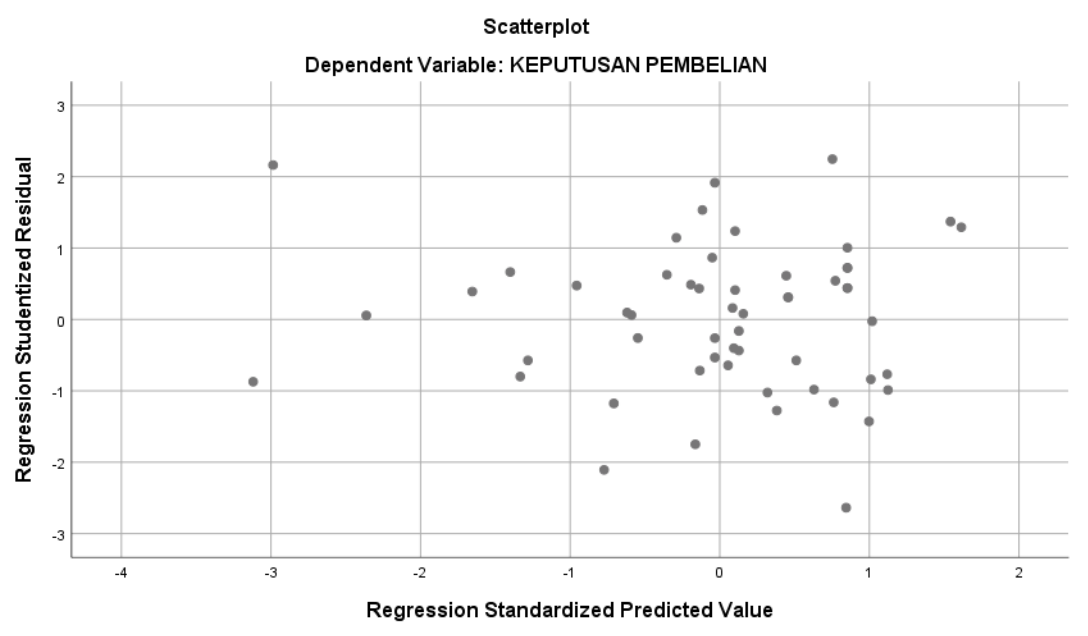

Gambar 1. Hasil uji Heterokedastisitas

Menurut gambar 1 dapat disimpulkan tidak terjadi heterokedasitas sebab titik-titik menyebar acak serta pola yang tidak jelas, maka uji heterokedasitas sudah terpenuhi.

\subsection{Uji regresi Linier Berganda}

Hasil linier Berganda terdapat dari tabel 3 seperti berikut :

Tabel 3. Hasil Uji Linier Berganda Coefficients $^{\mathrm{a}}$

\begin{tabular}{llllll}
\hline & \multicolumn{3}{c}{ Unstandardized Coefficients } & \multicolumn{2}{l}{$\begin{array}{l}\text { Standardized } \\
\text { Coefficients }\end{array}$} \\
\cline { 2 - 5 } & $\mathrm{B}$ & Std. Error & Beta & $\mathrm{T}$ & Sig. \\
\hline (Constant) & 11.278 & 4.239 & & 2.661 & .011 \\
Periklanan & .463 & .301 & .205 & 1.538 & .131 \\
Penjualan Pribadi & .746 & .367 & .302 & 2.033 & .047 \\
Hubungan Masyarakat & -.678 & .559 & -.157 & -1.212 & .231 \\
Promosi Penjualan & 1.258 & .459 & .325 & 2.741 & .009 \\
Pemasaran Langsung & .927 & .511 & .249 & 1.813 & .076 \\
\hline
\end{tabular}

Didapat hasil perhitungan bahwa menunjukkan constant 11.278 merupakan variabel keputusan pelanggan yang belum dipengaruhi variabel lainnya yakni Advertising (X1), personal selling (X2), public relations (X3), sales promotion (X4), direct marketing (X5) maka keputusan pelanggan 11.278.

Nilai konstanta sebesar 11,278 menyatakan bahwa variabel bebas yakni advertising (X1), personal selling (X2), public relations (X3), sales promotion (X4), direct marketing (X5) dalam keadaan konstan (tetap) maka keputusan pembelian sebesar 11,278

Koefisien regresi X1 (Advertising) sebesar 0,463 menunjukkan tiap penambahan 1 satuan pada variabel X1 (Advertising) maka meningkatkan nilai keputusan pelanggan (Y) yakni 0,463 . 
Koefisien regresi X2 (Personal Selling) yakni 0,746 bahwa tiap penambahan 1 satuan pada variabel X2 (Sales promotion) maka meningkatkan nilai keputusan pelanggan (Y) sebesar 0,746 .

Koefisien regresi X3 (Public relations) yakni -0,678 dan bernilai negatif yang apabila variabel X3 (Public relations) turun sebesar 1 satuan sehingga variabel dependen yakni keputusan pelanggan (Y) akan menurun juga sebesar -0,678

Koefisien regresi X4 (Sales promotion) sebesar 1,258 menunjukkan setiap penambahan 1 satuan pada variabel X4 (Sales promotion) maka meningkatkan nilai keputusan pelanggan (Y) sebesar 1,258 .

Koefisien regresi X5 (Direct marketing) sebesar 0,927 menunjukkan setiap penambahan 1 satuan pada variabel X5 (Direct Marketing) maka meningkatkan nilai keputusan pelanggan (Y) sebesar 0,927.(Fadila et al., 2021)

\subsection{Pengujian Hipotesis}

\section{a. Uji parsial t}

Tabel 4. Hasil parsial $t$

Coefficients $^{\mathrm{a}}$

\begin{tabular}{|c|c|c|c|c|c|}
\hline & \multicolumn{2}{|c|}{$\begin{array}{l}\text { Unstandardized } \\
\text { Coefficients }\end{array}$} & \multicolumn{2}{|l|}{$\begin{array}{l}\text { Standardized } \\
\text { Coefficients }\end{array}$} & \multirow[b]{2}{*}{ Sig. } \\
\hline & $\mathrm{B}$ & Std. Error & Beta & $\mathrm{T}$ & \\
\hline (Constant) & 11.278 & 4.239 & & 2.661 & .011 \\
\hline Periklanan & .463 & .301 & .205 & 1.538 & .131 \\
\hline Penjualan Pribadi & .746 & .367 & .302 & 2.033 & .047 \\
\hline Hubungan Masyarakat & -.678 & .559 & -.157 & -1.212 & .231 \\
\hline Promosi Penjualan & 1.258 & .459 & .325 & 2.741 & .009 \\
\hline Pemasaran Langsung & .927 & .511 & .249 & 1.813 & .076 \\
\hline
\end{tabular}

Pengaruh variabel Advertising (X1) Didapat nilai t hitung variabel advertising (X1) adalah 1,538<2,009. Dan signifikasinya 0,131>0,05, Maka variabel advertising (X1) tidak berpengaruh signifikan pada keputusan pelanggan $(\mathrm{Y})$. Hasil ini sesuai dengan penelitian sebelumnya oleh (Ningsih \& Hati, 2017).

Pengaruh variabel personal selling (X2 dengan thitung $2.033>2,009$. serta signifikasinya $0,047<0,05$, Maka variabel personal selling (X2) berpengaruh signifikan pada keputusan pelanggan $(\mathrm{Y})$.

Pengaruh variabel public relations (X3) dengan nilai thitung -1.212 < 2,0099. Dan signifikasinya $0,231>0,05$, maka variabel public relations (X3) tidak berpengaruh signifikan pada keputusan pelanggan (Y) .

Pengaruh variabel sales promotion (X4) Didapat thitung $2.741>2,009$. Dan signifikasinya $0,004<0,05$, Sehingga variabel sales promotion $(\mathrm{X} 4)$ berpengaruh signifikan pada keputusan pelanggan (Y). Hasil ini sesuai dengan penelitian sebelumnya oleh (Windusara, 2015), (Khusna \& Oktafani, 2017), (Ningsih \& Hati, 2017), (Yulaiqah \& 
Widaningsih, 2018), (Jaelani, 2018), yang menyatakan bahwa terdapat pengaruh sales promotion kepada keputusan pelanggan.

Pengaruh variabel direct marketing (X5) Didapat thitung $1.813<2,009$. Dan signifikasinya $0,076>0,05$, maka variabel direct marketing (X5) tidak berpengaruh signifikan pada keputusan pelanggan $(\mathrm{Y})$.

\section{b. Uji simultan f}

Tabel 5. Hasil analisis simultan $\mathbf{f}$

\begin{tabular}{llllll}
\multicolumn{7}{c}{ ANOVA $^{\mathrm{a}}$} \\
\hline & Sum of Squares & Df & Mean Square & F & Sig. \\
\hline Regression & 831.131 & 5 & 166.226 & 11.814 & $.000^{\mathrm{b}}$ \\
Residual & 689.414 & 49 & 14.070 & & \\
Total & 1520.545 & 54 & & & \\
\hline
\end{tabular}

Hasil analisis dari tabel 4 diperoleh Fhitung yakni sebesar 11.814 serta signifikansi 0,000. Dengan signifikansi lebih kecil terhadap nilai $\alpha 0,05$ maka Ho ditolak. Sehingga simultan/keseluruhan dari model regresi yang diperoleh sudah signifikan.

\subsection{Koefisien Determinan $\left(R^{2}\right)$}

Dari analisis uji koefisien determinan didapatkan hasil seperti berikut:

Tabel 6. Hasil Koefisien Determinan

Model Summary ${ }^{b}$

\begin{tabular}{lllll} 
& $\mathrm{R}$ & R Square & Adjusted R Square & Std. Error of the Estimate \\
\hline 1 & $.739^{\mathrm{a}}$ & .547 & .500 & 3.751
\end{tabular}

Predictors: (Constant), Pemasaran Langsung, Periklanan, Promosi Penjualan, Hubungan Masyarakat, Penjualan Pribadi

Dependent Variable: Keputusan pelanggan

Hasil dari perhitungan didapat R-Square yakni 0,547. Hasil tersebut dapat diketahui bahwa sebesar 54,7\% keputusan pelanggan menggunakan produk/jasa PT. Pos Indonesia Soreang dipengaruhi bauran promosi yang dilakukan, serta sisanya 45,3\% dipengaruhi oleh variabel lain .

\section{PEMBAHASAN}

\section{Pengaruh Advertising Terhadap Keputusan Pelanggan}

Variabel Advertising (X1) tidak berpengaruh signifikan pada keputusan pelanggan (Y) (Ningsih \& Hati, 2017). Hal ini dapat terjadi karena Pos Indonesia masih kurang mengiklankan 
produknya di media cetak maupun online dan para konsumen masih ada yang belum tau akan produk baru atau yang telah ada yang ditawarkan oleh Pos Indonesia .

\section{Pengaruh Personal Selling Terhadap Keputusan Pelanggan}

Variabel personal selling (X2), berpengaruh signifikan pada keputusan pelanggan (Y). Dengan para pegawai pelayanan Pos Indonesia Cabang Soreang yang sering menawarkan produk-produk dari Pos Indonesia yang lainnya kepada konsumen yang sedang menggunakan layanan jasa. Hal tersebut dapat menarik konsumen untuk menggunakan produk yang lainnya sehingga dapat memberikan keuntungan bagi perusahaan . hasil ini sesuai dengan penelitian sebelumnya yang dilakukan oleh (Yunaida \& Nurlaila Hanum, 2019)

\section{Pengaruh Public Relations Terhadap Keputusan Pelanggan}

Variabel public relations (X3) tidak berpengaruh signifikan pada keputusan pelanggan (Y). Dikarenakan menurut konsumen, Pos indonesia belum sering melakukan kegiatan yang mengupayakan hubungan dengan masyarakat.

\section{Pengaruh Sales Promotion Terhadap Keputusan Pelanggan}

Variabel sales promotion (X4), berpengaruh signifikan pada keputusan pelanggan (Y). Hal ini karena Pos Indonesia sering mengadakan promosi seperti memberi voucher atau diskon terhadap para pelanggan sehingga pelanggan tertarik untuk menggunakan layanan jasa Pos Indonesia kembali di kemudian hari. Sesuai dengan penelitian sebelumnya yang dilakukan oleh (Sandy, 2014).

\section{Pengaruh Direct Marketing Terhadap Keputusan Pelanggan}

Variabel direct marketing (X5) tidak berpengaruh signifikan pada keputusan pelanggan (Y). Hal tersebut berarti bahwa variabel direct marketing tidak mempengaruhi keputusan pelanggan karena masih ada pelanggan yang belum tertarik terhadap produk yang ditawarkan langsung oleh Pos Indonesia.

Berdasarkan hasil perhitungan bahwa bauran promosi mempunyai pengaruh yang relevan terhadap keputusan pelanggan menggunakan jasa Pos Indonesia Soreang, Bisa disimpulkan bahwa besarnya pengaruh bauran promosi terdiri variabel advertising, personal selling, public relations, sales promotion, direct marketing atas keputusan pelanggan diperoleh nilai cukup tinggi mencapai $54,7 \%$. serta sisanya $45,3 \%$ dipengaruhi faktor lainnya yang tidak termasuk kedalam penelitian.

\section{KESIMPULAN}

Berdasarkan hasil penelitian yang sudah dilakukan bahwa dari regresi berganda bahwa variabel advertising, public relations dan Direct marketing tidak mempunyai pengaruh terhadap keputusan pelanggan. Jika perusahaan tidak memperbaiki atau meningkatkan dalam periklanan, hubungan masyarakat dan pemasaran langsung, dengan begitu para pelanggan akan 
meninggalkan bahkan dapat beralih pada layanan jasa pesaing. Sedangkan variabel personal selling dan sales promotion mempunyai pengaruh terhadap keputusan pelanggan. Jika perusahaan mempertahankan promosi dan meneruskan penjualan pribadinya, Hal tersebut dapat mempengaruhi keputusan pelanggan untuk menggunakan jasa Pos Indonesia

\section{SARAN}

Bagi perusahaan sebaiknya melakukan kegiatan promosi dengan e-commerce seperti memberikan biaya pengiriman gratis kepada para pembeli yang akan memilih pengiriman menggunakan Pos Indonesia, hal tersebut juga dapat membantu para penjual online juga para UMKM. Dan sebaiknya PT. Pos Indonesia dapat melakukan inovasi untuk mempromosikan produk yang ditawarkan. Agar konsumen dapat tertarik kembali menggunakan layanan jasa Pos Indonesia

Bagi Penilitian Selanjutnya, Penelitian ini diteliti pada satu variabel yang mempengaruhi keputusan pelanggan, sehingga diharuskan adanya variabel lain dalam penelitian selanjutnya yang berpengaruh.

\section{REFERENSI}

Fadila, H. A., Astuningsih, S. E., \& Others. (2021). Pengaruh Bauran Pemasaran Terhadap Keputusan Pembelian Jilbab Rabbani pada Mahasiswi Fakultas Ekonomi dan Bisnis Islam IAIN Tulungagung. Jurnal Manajemen Dan Bisnis Indonesia, 7(1), 108-119. http://jurnal.unmuhjember.ac.id/index.php/JMBI/article/view/4891

Jaelani, E. (2018). Pengaruh Bauran Promosi terhadap Keputusan Pembelian Online pada Konsumen Tokopedia di Bandung. Jurnal Sains Manajemen \& Akuntansi, X(2), 57-64.

Kementerian Komunikasi dan Informatika. (n.d.). Retrieved October 1, 2021, from https://kominfo.go.id/content/detail/16770/kemkominfo-pertumbuhan-e-commerceindonesiacapai-78-persen/0/sorotan_media

Khusna, G. K., \& Oktafani, F. (2017). Pengaruh Bauran Promosi Terhadap Keputusan Pembelian Dunkin'Donut. Jurnal Ekonomi, Bisnis \& Enterpreneur, 11(1), 27-36. https://core.ac.uk/download/pdf/234663429.pdf

Kotler. Amstrong, G. (2012). Prinsip-prinsip Pemasaran Edisi 13 Jilid 1. Erlangga.

Martono, N. (2010). Metode Penelitian Kuantitatif: Analisis Isi dan Analisis Data Sekunder. PT. Raja Grafindo Persada.

Ningsih, Y. P., \& Hati, S. W. (2017). PENGARUH BAURAN PROMOSI TERHADAP KEPUTUSAN PEMBELIAN PRODUK ACCU YUASA YANG DIPROMOSIKAN DISTRIBUTOR PT RIAU INDOTAMA ABADI di BATAM. Journal of Applied Business Administration, 1(1), 10-18. https://doi.org/10.30871/jaba.v1i1.1255 
Sandy, F. (2014). Pengaruh Bauran Promosi Terhadap Keputusan Pembelian (Survei pada Mahasiswa Jurusan Bisnis Angkatan 2010-2012 Fakultas Ilmu Administrasi Pengguna Indosat di Universitas Brawijaya ). Jurnal Administrasi Bisnis (JAB), 9(2), 1-10.

sugiyono. (2018). Metode Penelitian Kuantitatif , Kualitatif, dan R\&D. Alfabeta.

Tjiptono, F. (2014). Pemasaran Jasa- Prinsip, Penerapan, dan Penelitian. ANDI.

Tjiptono, F. (2015). Strategi Pemasaran EDISI 4. ANDI.

Wantu, D. (2014). PENGARUH BAURAN PROMOSI TERHADAP KEPUTUSAN PELANGGAN MENGGUNAKAN JASA PT. POS INDONESIA (PERSERO) CABANG GORONTALO. In Universitas Negri Gorontalo.

Windusara, N. B. D. (2015). Pengaruh Bauran Promosi Terhadap Keputusan Pembelian OPPO SMARTPHONE. E-Jurnal Manajemen Unud, 4(12), 4160-4185.

Yulaiqah, F., \& Widaningsih, S. (2018). PENGARUH BAURAN PROMOSI TERHADAP KEPUTUSAN PEMBELIAN KONSUMEN (Studi Kasus Pada PT Soka Cipta Niaga Bandung). E-Proceeding of Applied Science, 4(3), 1012-1018.

Yunaida, E., \& Nurlaila Hanum. (2020). Pengaruh Bauran Promosi terhadap Keputusan Pembelian Perumahan PT. Pillar Tamiang Konstruksi Aceh Tamiang. Jurnal Manajemen Dan Keuangan, 8(3), 389-401. https://doi.org/10.33059/jmk.v8i3.2399 